
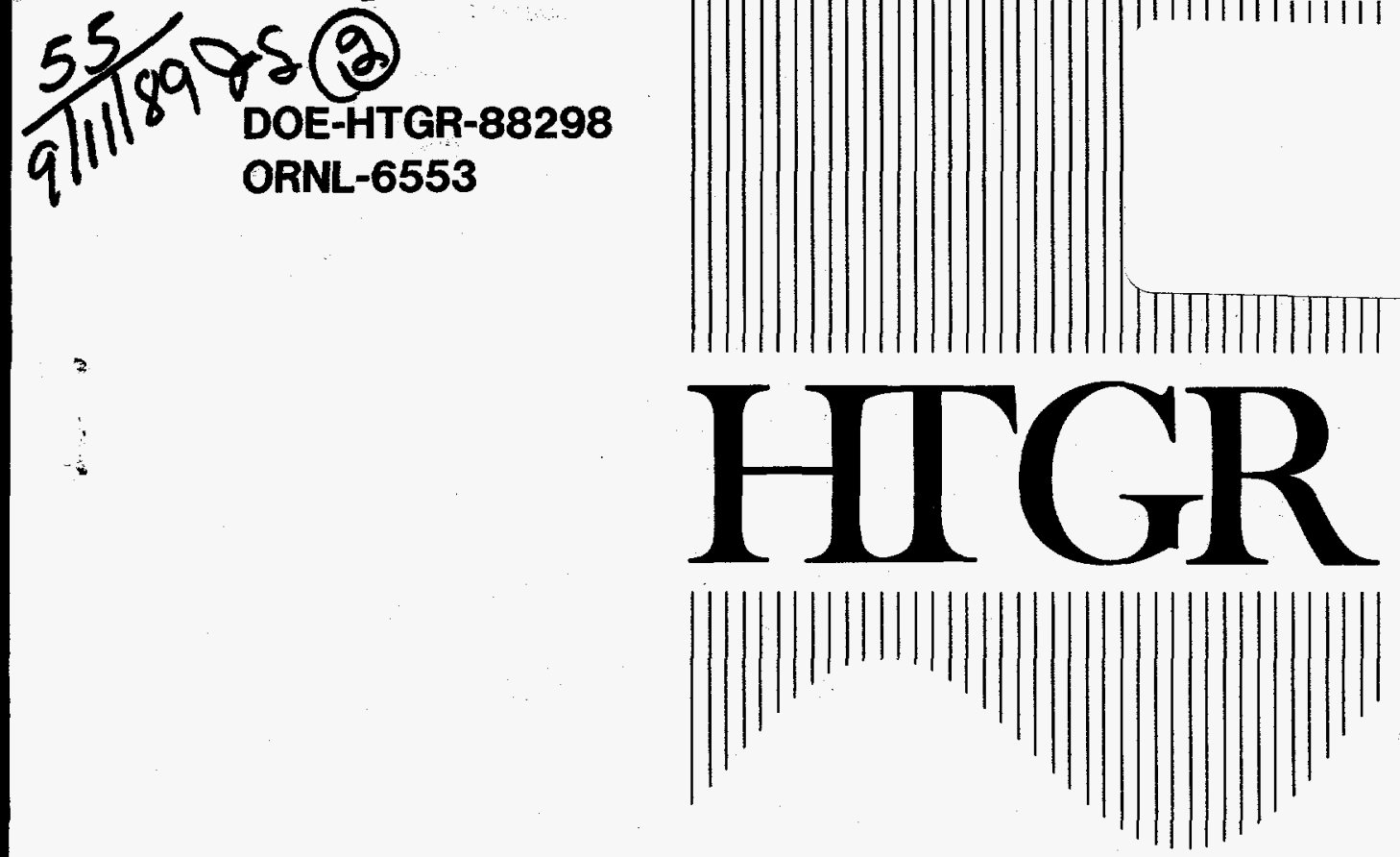

\title{
AN EVALUATION OF THE SUITABILITY OF LASER-INDUCED FLUORESCENCE FOR MEASUREMENTS OF FISSION-PRODUCT IODINE SORPTIVITY IN THE MHTGR
}

AUTHORS/CONTRACTORS

Oak Ridge National Laboratory

S. A. Sherrow

OAK RIDGE NATIONAL LABORATORY

Oak Ridge, Tennessee 37831-6285

operated by

MARTIN MARIETTA ENERGY SYSTEMS, INC.

for the

UNITED STATES DEPARTMENT OF ENERGY
DO NOT MEROFLM

COVER

HSiER 
This report has been reproduced directly from the best available copy.

Available to DOE and DOE contractors from the Office of Scientific and Technical Information, P.O. Box 62, Oak Ridge, TN 37831; prices available from (615) 576-8401, FTS 626-8401.

This report was prepared as an account of work sponsored by an agency of the United States Government. Neither the United States Government nor any agency thereof, nor any of their employees, makes any warranty, express or implied, or assumes any legal liability or responsibility for the accuracy, completeness, or usefulness of any information, apparatus, product, or process disclosed, or represents that its use would not infringe privately owned rights. Reference herein to any specific commercial product, process, or service by trade name, trademark, manufacturer, or otherwise, does not necessarily constitute or imply its endorsement, recommendation, or favoring by the United States Government or any agency thereof. The views and opinions of authors expressed herein do not necesserily state or reflect those of the United States Government or any agency thereof.

\section{DO NOT MICROFLLM THIS PAGE}


DOE - HTGR - 88298

ORNL- 6553

Dist. Category UC -522

MHTGR Technology Program

\begin{abstract}
AN EVALUATION OF THE SUITABILITY OF LASER-INDUCED FLUORESCENCE FOR MEASUREMENTS OF FISSION PRODUCT IODINE SORPTIVITY IN THE MHTGR
\end{abstract}

S. A. Sherrow

Chemical Technology Division

Milestone 1601.2.13

Date Published - July 1989

Prepared by the

OAK RIDGE NATIONAL LABORATORY

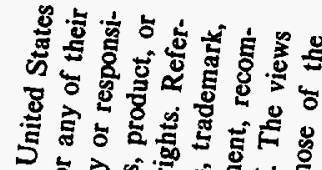

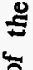

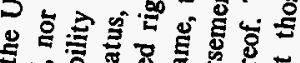

宁䔎要

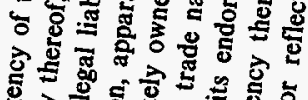

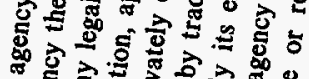

ร

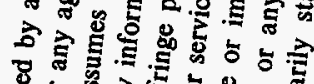

Oak Ridge, Tennessee 37831-6285 operated by MARTIN MARIETTA ENERGY SYSTEMS, INC.

for the

U.S. DEPARTMENT OF ENERGY under contract DE-ACO5-840R21400 


\section{DISCLAMMER}

Portions of this document may be illegible in electronic image products. Images are produced from the best available original document. 
CONTENTS

SUMMARY . . . . . . . . . . . . . . . . . . . . . . 1

1. OBJECTIVE . . . . . . . . . . . . . . . . . . . 1

2. INTRODUCTION . . . . . . . . . . . . . . . . . . . 2

3. ASPECTS OF LIF . . . . . . . . . . . . . . . . . . 3

4. EXPERIMENTS WITH IODINE . . . . . . . . . . . . . . . . 5

5. SIGNAL CALCULATIONS . . . . . . . . . . . . . . . . 10

6. ALTERNATIVES TO LIF . . . . . . . . . . . . . . . . 16

7. CONCLUSIONS . . . . . . . . . . . . . . . . . . . . 17

8. REFERENCES AND NOTES . . . . . . . . . . . . . . . . 18 


\section{AN EVALUATION OF THE SUITABILITY OF LASER-INDUCED FLUORESCENCE FOR MEASUREMENTS OF FISSION PRODUCT IODINE \\ SORPTIVITY IN THE MHTGR}

S. A. Sherrow

\section{SUMMARY}

Experiments and calculations indicate that laser-induced fluorescence (LIF) lacks the sensitivity needed for sorptivity measurements of $I_{2}$ or other molecular species at partial pressures below $10^{-11} \mathrm{~atm}$. Although the technique may have sufficient sensitivity for measurements of atomic species, the species of interest are, in all likelihood, not atomic. Methods of measurement which would allow the determination of species are proposed.

\section{OBJECTIVE}

In order to predict the release of fission products from the modular high-temperature gas-cooled reactor (MHTGR) under accident conditions, such as a cooling system leak, it is necessary to know the distribution of fission product species within the system. One area of particular concern is the extent to which fission products removed from circulation (by adsorption or reaction with cooling circuit components) are re-entrained following a change in temperature or pressure. Thiz experimental program seeks to address that area by supplying data on fission product sorption and desorption by primary circuit alloys under conditions which approximate, as nearly as possible, those expected for the MHTGR. 


\section{INTRODUCTION}

The determination of sorption/desorption isotherms is, in principle, straightforward. The vapor pressure (or some related quantity) of the species of interest is measured in the presence of the adsorbent, and the quantity is compared to a reference measurement. The problem in practice is that the vapor pressures expected for key fission product species are on the order of $10^{-14} \mathrm{~atm}$; ordinary methods of vapor pressure determination lack the sensitivity for quantitative measurements at this level.

A previous evaluation of LIF for fission product sorption/desorption measurements was based on data obtained for cesium and on literature reports of very low detection limits achieved for some species by LIF.? Although molecular iodine was the experimental focus of this evaluation, the discussion of the technique and the conclusion apply equally to other species. In the sections that follow, the technique of LIF will be described and the factors which determine detection limits will be discussed. The equipment and procedures used for iodine measurements will be described. An approximate formula for calculating signal levels will be presented with numerical examples. Finally, the problems inherent in the LIF approach will be addressed, and methods which might more readily provide useful data will be discussed. 


\section{ASPECTS OF LIF}

Fluorescence is radiation emitted by an atom or molecule as it relaxes from an excited state. The technique of LIF employs a laser to prepare the excited state. The laser wavelength must coincide with an allowed transition (for our purposes, an electronic absorption) of the sample. The emission may be at the same wavelength as the excitation (resonance fluorescence) or at a different wavelength, and also corresponds to an allowed transition. The specific transition energies and the selection rules that determine which transitions are permitted vary from one species to the next; thus a laser/detector combination that yields adequate results for one species may be wholly unsuited for another.

The observed signal in LIF experiments may be viewed as the product of three factors: the probability that a laser photon is absorbed, the probability that a photon is emitted at the selected detection wavelength, and the combined efficiencies of the collection optics and detector. The last factor is determined by geometry and hardware and has nothing to do with the sample. The first two quantities depend on the sample species itself, on the experimental conditions, and on the concentration (number density) of the sample.

The tendency of a sample species to undergo a transition from one particular energy level to another is called the transition probability; this is a fixed property of the sample. The number of photons absorbed by a given sample is the product of the transition probability, the intensity of the light source, and the number of available sample atoms or molecules. In the case of an atomic sample, there are only electronic energy levels. Even at fairly high $\left(1000^{\circ} \mathrm{C}\right)$ temperatures, most of the 
atoms are in the lowest electronic state and are available for an excitation to another level. Molecules possess, in addition to electronicenergy, vibrational and rotational energy. Excitation is from a particular vibration/rotation sublevel of the ground electronic state to a particular vibration/rotation sublevel of the excited electronic state. Because the molecules are thermally distributed among the vibration/ rotation sublevels, the number found in any given state is a function of temperature and of the particular vibration/rotation energies of the molecule. Typically, the number of molecules available to undergo a specified transition is a small fraction of the total sample. Also, because the number of possible energy states for a molecule is much greater than that for an atom, the probability of a transition to any one state is often much smaller than the probability of an atomic transition. An atom or molecule in an excited state may dispose of its excess energy in a number of ways: it may ionize or dissociate, it may react or otherwise interact with another species, or it may emit. The likelihood of the first two processes may be minimized by the selection of the excited state and the laser power and by controlling the concentration and composition of the background gas. In the absence of other relaxation paths, the tendency of the sample to return via emission to the initial or to an intermediate state is governed by the transition probability. Because of the disparity in the number of possible transitions, atomic emissions appear as a few sharp lines while molecular emissions appear as a series of bands, each of which is composed of many closely spaced lines. 
What should be clear from the preceding discussion is that the LIF experiment must be tailored to the species of interest. The sample itself dictates what laser wavelength(s) may be used for excitation. Molecular samples allow some latitude in wavelength selection, but it comes at the expense of intensity. Limits of detection vary with experimental conditions and with hardware, and the ultimate lower limits are established by fixed transition probabilities.

\section{EXPERIMENTS WITH IODINE}

The purpose of the LIF experiments with iodine was to ascertain whether the laser equipment already purchased for the program and the LIF technique itself could be expected to yield reliable data for iodine sorptivity at moderate $\left(500^{\circ} \mathrm{C}\right)$ temperatures and very low $\left(10^{-14} \mathrm{~atm}\right)$ partial pressures.

The laser equipment used for these experiments was a Quanta-Ray DCR 1-A Nd:YAG, which was purchased by General Atomics for LIF studies of cesium and was inherited by this program. The laser fundamental is in the infrared at $1064 \mathrm{~nm}$; frequency doubling crystals for generating second $(532-\mathrm{nm})$ and third $(355-\mathrm{nm})$ outputs were supplied with the laser. Also supplied with the laser was a Quanta-Ray PDL-I dye laser; either of the harmonics could be used to pump the dye laser so that any laser wavelength between 355 and $800 \mathrm{~nm}$ could be generated. The detection equipment was selected for sensitivity and response over a wide range of wavelengths (200-900 nm) and consisted of a Jarrel1-Ash 0.27-m spectrograph, a Princeton Applied Research model 1421 intensified diode array 
detector, and a model 1463 optical multichannel analyzer. The spectrograph was adjusted to reject the laser frequency and disperse the remainder of the incoming signal; the array detector, after calibration with a standard lamp, registered signal intensity as a function of wavelength. The detector exposure time could be varied from $17 \mathrm{~ms}$ to about $10 \mathrm{~min}$; any number of exposures could be added to improve the signal to noise. A schematic drawing of the experimental arrangement is shown in Fig. 1. Energy level diagrams and possible fluorescence schemes for atomic ${ }^{2}$ and molecular ${ }^{3}$ iodine are shown in Figs. 2 and 3 . The longest wavelength atomic lodine absorption from the ground state is at $183 \mathrm{~nm}$. This wavelength can be obtained from excimer lasers or from frequency doubling a dye laser; it is not possible to obtain wavelengths in this region with the existing laser equipment. Iodine has a strong absorption that begins at $636 \mathrm{~nm}$ and extends beyond $500 \mathrm{~nm}$; any laser wavelength in this region could be used to excite fluorescence. The YAG harmonic at $532 \mathrm{~nm}$ was selected for excitation because of its stability and ease of generation. At this wavelength, the laser excites $I_{2}$ molecules from the $v=0, J=51$ and 54 sublevels of the ground electronic state to the $\mathrm{v}^{\prime}=32, \mathrm{~J}^{\prime}=50$ and 55 sublevels of the excited state." Emission is from $v^{\prime}=32$ to all possible vibrational levels of the ground electronic state.

Iodine samples were prepared by resubliming purified iodine into cold fingers attached to evacuated pyrex or quartz gas cells. Iodine vapor pressures from $10^{-4}$ to $10^{-9}$ atm were controlled by adjusting the temperature of the cold finger; $;^{5}$ the gas cells were at ambient $\left(20^{\circ} \mathrm{C}\right)$ temperature. To ensure a constant $I_{2}$ vapor pressure it was necessary, 
ORNL DWG $89-68$

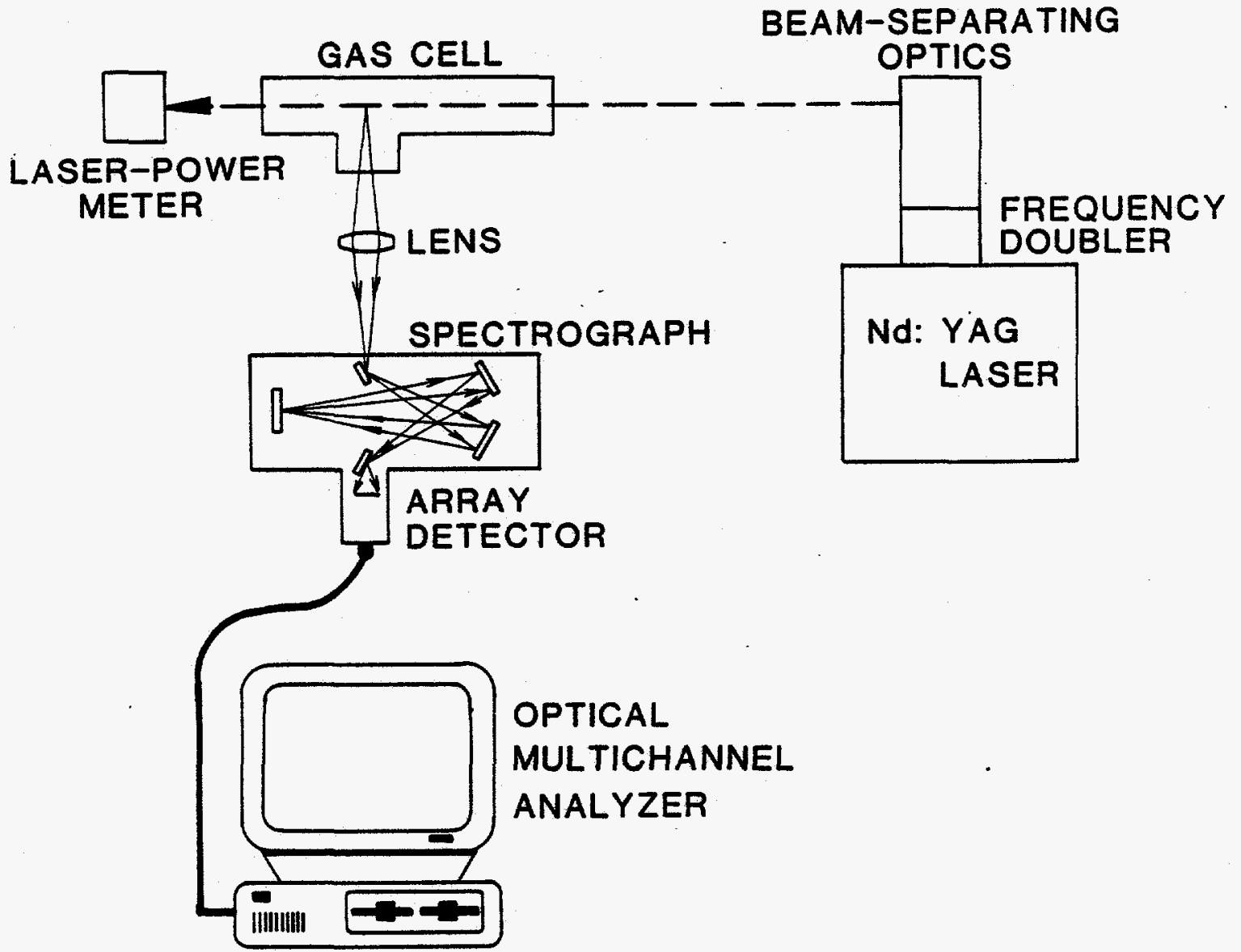

Fig. 1. Experimental configuration for LIF measurements of $I_{2}$. (The dashed line indicates the laser path.) 
ORNL DWG 89-67

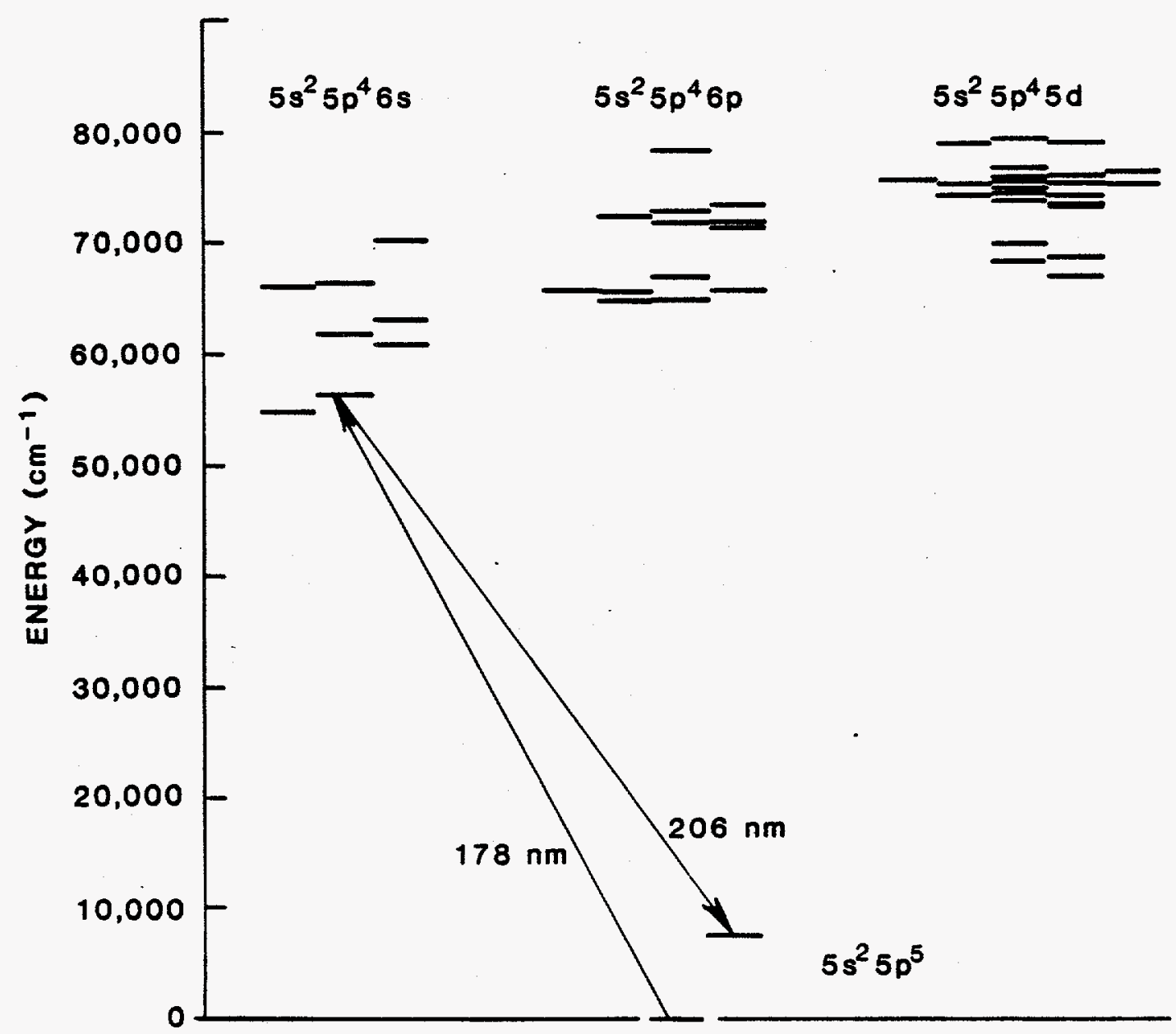

Fig. 2. Simplified energy level diagram showing the lowest energy levels of I atoms.

(The upward arrow indicates excitation; the downward arrow indicates fluorescence. Single photon transitions from the $5 s^{2} 5 p^{5}$ ground state to the $5 s^{2} 5 p^{4} 6 p$ state are forbidden.) 
ORNL DWG 89-69

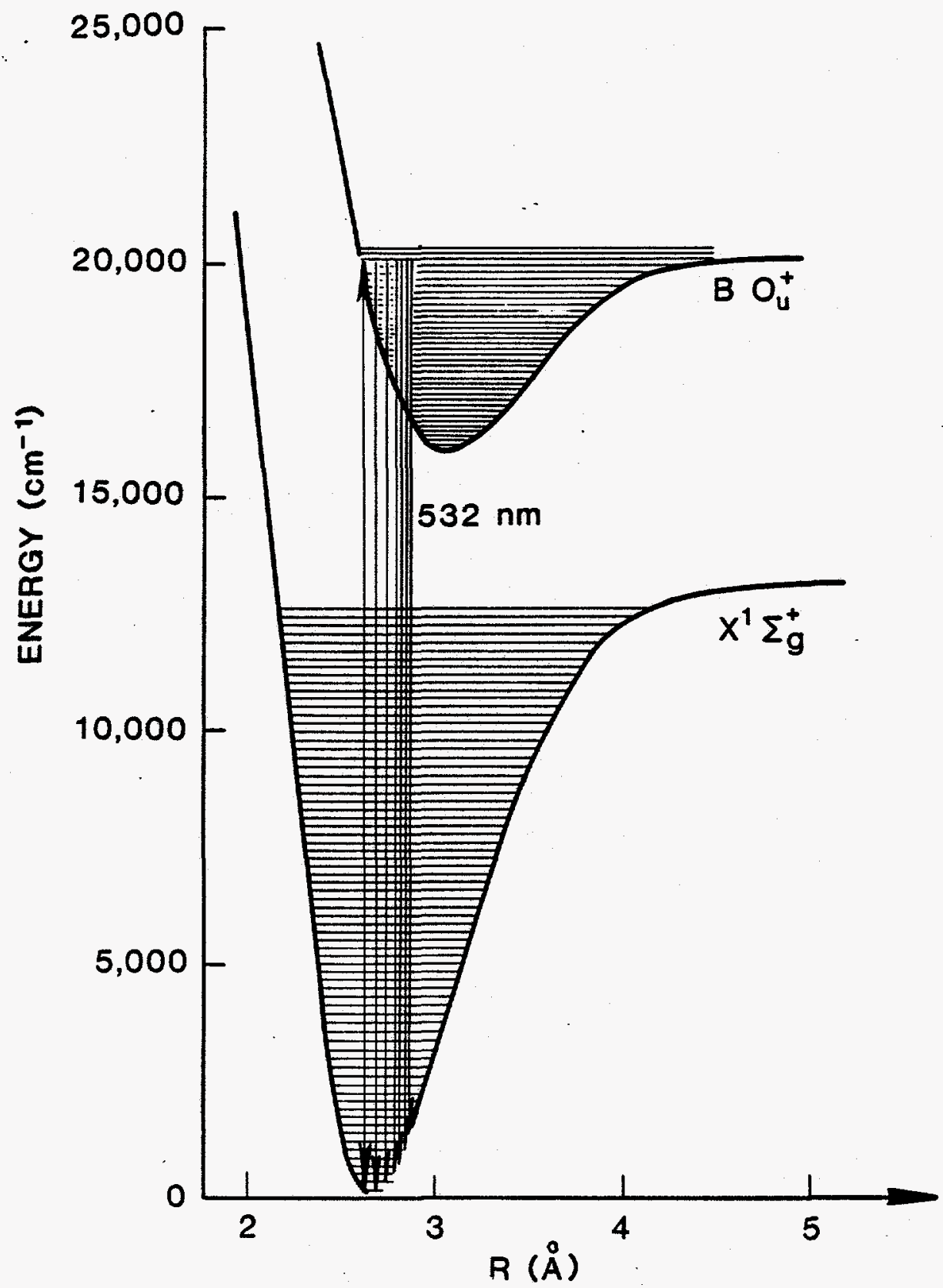

Fig. 3. Simplified energy level diagram for $I_{2}$.

[The vibrational spacings shown are $=213 \mathrm{~cm}^{-1}$ for the lower state and $125 \mathrm{~cm}^{-1}$ for the upper state. Each vibrational level is further subdivided into rotational levels (not shown). The upward arrow indicates $532 \mathrm{~nm}$ excitation; the downward arrows indicate the first few lines of the fluorescence series.] 
particularly at the lower pressures, to maintain the vapor in contact with the temperature-controlled solid. Very small pressures of $I_{2}$ cannot be maintained in sealed cells because of reaction with residual gases and other trace impurities.

Spectra for various $I_{2}$ vapor pressures are shown in Figs. 4-6. Exposure times were varied as necessary in order to obtain acceptable signals. Figure 6 shows the spectrum of $2 \times 10^{-9}$ atm $I_{2}$ measured with the maximum exposure time of $10 \mathrm{~min}$. This was the smallest quantity measured during these experiments. The 10-min limit on exposure was due to saturation of the detector by dark current at the lowest operating temperature; this represented the operating limit of the detector, and no substantial improvement could be made with this system. The apparent lower limit of $10^{-9} \mathrm{~atm}$ was several orders of magnitude above the region of interest for the sorption/desorption studies. Detection limits must be even higher at elevated temperatures because dissociation reduces the number of $I_{2}$ molecules.

\section{SigNaL GaLCULATIONS}

In the first section it was noted that detection limits are determined by experimental hardware and conditions and by the properties of the sample species itself. We have established that the lower limit of detection for $I_{2}$ in our system is $-10^{-9} \mathrm{~atm}$. In order to determine whether and how improvement might be gained, it is useful to examine the factors contributing to the signal. 
ORNL DWG 89-356

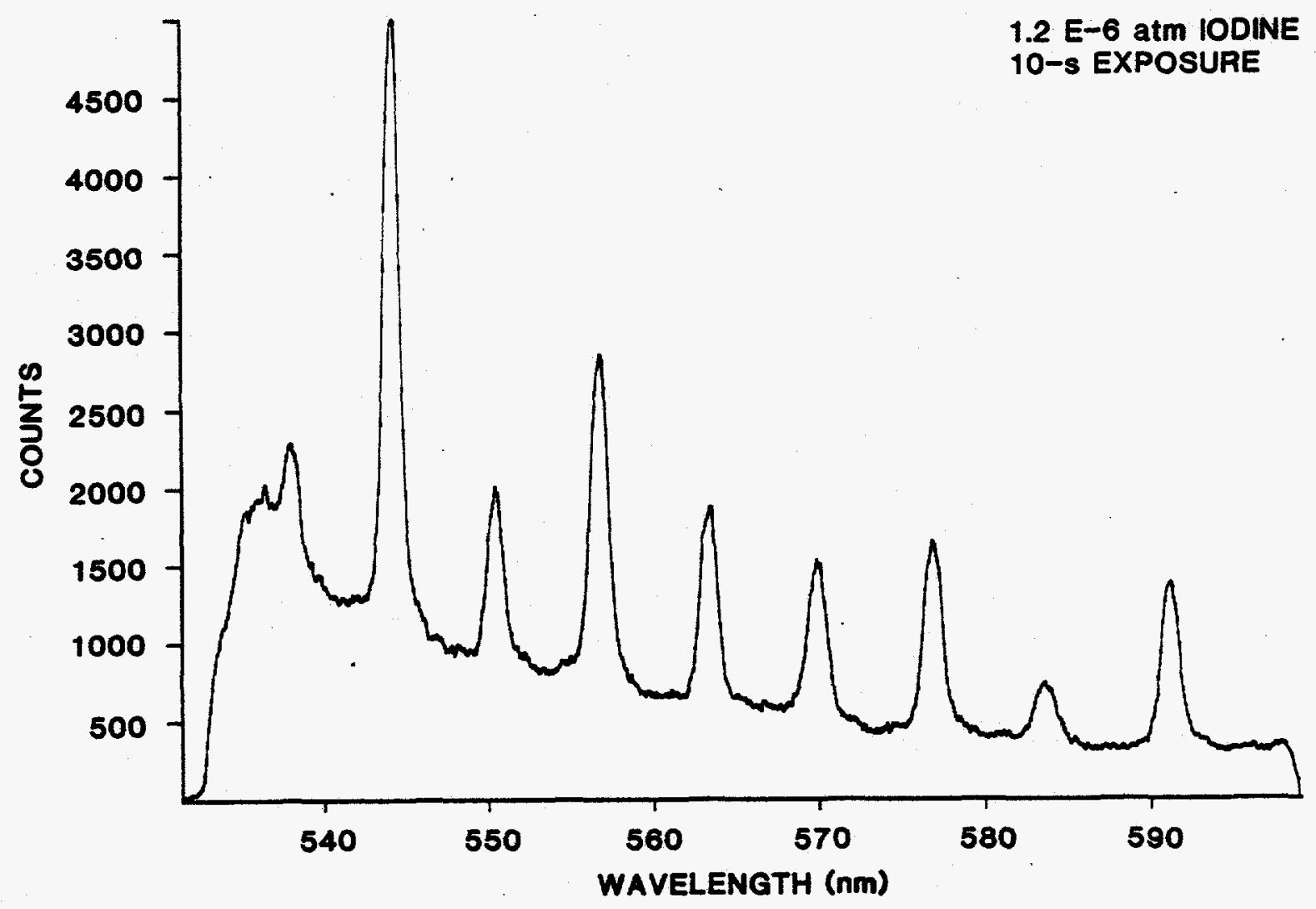

Fig. 4. LIF spectrum of $1.2 \times 10^{-6}$ atm $I_{2}$. The most intense line is the transition which terminates in $v-2$ of the ground state. (These data were obtained with a $10-\mathrm{s}$ detector exposure and $150 \mathrm{~mJ}$ per pulse laser energy.) 


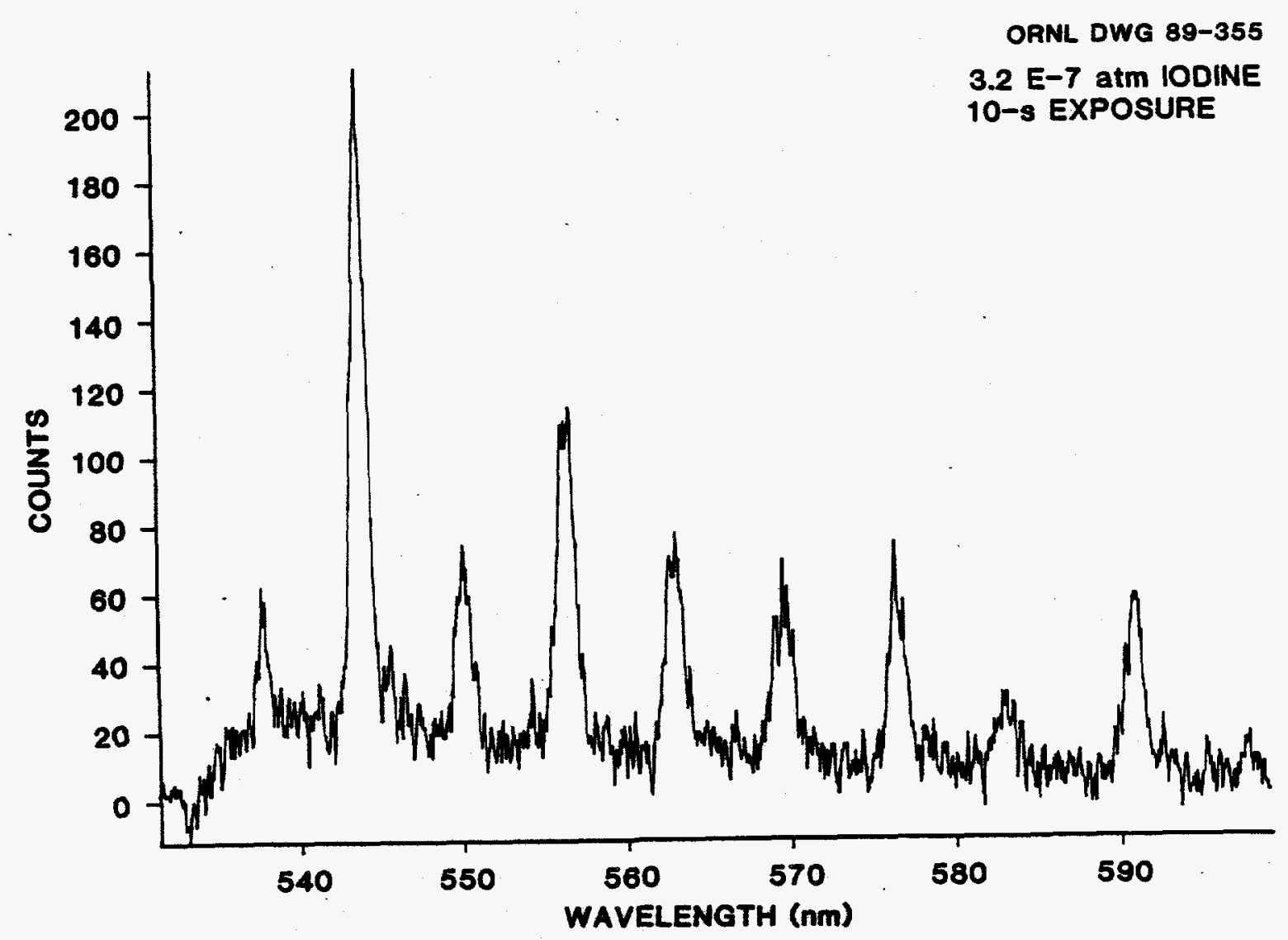

Fig. 5. IIF spectrum of $3.2 \times 10^{-7}$ atm $I_{2}$; data were obtained with a $10-\mathrm{s}$ detector exposure and $40 \mathrm{~mJ}$ per pulse. laser energy. 
ORNL. DWG 89-354

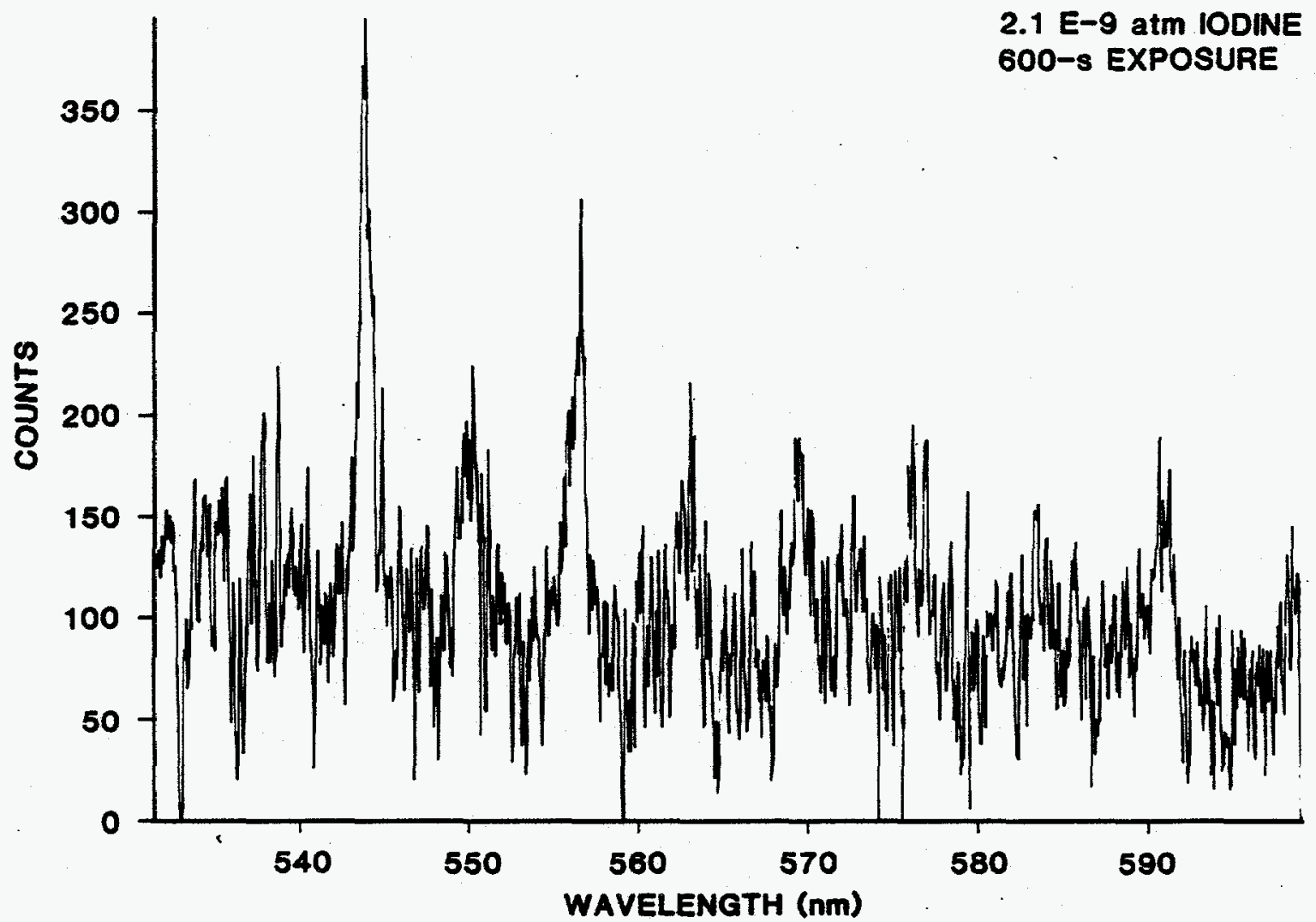

Fig. 6. LIF spectrum of $2.1 \times 10^{-9}$ atm $I_{2}$; data were obtained with a 10-min detector exposure and $40 \mathrm{~mJ}$ per pulse laser energy. 
The LIF signal, in detector counts per second, is given by

$$
S=\alpha N \frac{E}{2\left(E+E_{s}\right)} D A Q, 6
$$

where

$N=$ the number density of sample molecules,

$V=$ the sampled volume ( $1 \mathrm{cc}$ ),

$\alpha=$ the fraction of molecules capable of absorbing a photon.

For atomic samples, $\alpha$ is usually unity; for heavy diatomics such as $\mathrm{I}_{2}$, it is about 0.01 . The product aNV is the number of atoms or molecules actually being observed.

$E$ is the intensity of the laser, and $E_{s}$ is half the intensity needed to saturate the transition. $E_{s}$ is related to the absorption probability and is typically about $10^{6} \mathrm{~W} / \mathrm{cm}^{2}$. At $E-E_{s}$, we assume a steady excited population of one-fourth of the available molecules; in the limit of infinite laser power, this fraction increases to one-half. $D$ is the duty cycle of the laser, the fraction of time that the laser is on (pulse duration multiplied by repetition rate). Pulsed lasers achieve very high peak powers by delivering their energy in short bursts. Our laser, for example, delivers $0.1 \mathrm{~J}$ in $10 \mathrm{~ns}$ at $10 \mathrm{~Hz}$. The intensity is $10^{7} \mathrm{~W} / \mathrm{cm}^{2}$, but the duty cycle is $10^{-7}$. Although $\mathrm{CW}$ lasers provide a much lower peak power (not enough to saturate), they have a duty cycle of unity. The result is that for experiments lasting 1 s or longer, comparable signals are obtained from pulsed or CW lasers having the same average power. The factor $\alpha N V E D / 2\left(E+E_{s}\right)$ is a time-averaged number of molecules excited in $1 \mathrm{~s}$.

$A$ is the Einstein coefficient for spontaneous emission; ${ }^{8}$ multiplied by the number of excited molecules, it yields the signal photon emission 
rate. Spontaneous emission probabilities for $I_{2}$ are on the order of $10^{4} \mathrm{~s}^{-1}$ for a single strong line and $10^{6} \mathrm{~s}^{-1}$ for the entire series from a single upper state. For allowed atomic transitions, typically $A=10^{8} s^{-1}$.

Signal photons are emitted in all directions; the fraction collected and directed to the detector is given by $f$. With a fast collection lens and high throughput optical configuration, as many as 0.18 of the emitted photons may be transmitted to the detector. $Q$ is the detector quantum efficiency, the number of signal counts produced for each photon detected. Detector efficiencies vary widely, and the efficiency of a single detector may vary with wavelength. For a broadband detector such as ours, a quantum efficiency of about 78 at $550 \mathrm{~nm}$ is typical.

An $I_{2}$ pressure of $10^{-11}$ atm corresponds to a room temperature number density of $10^{8}$ molecules/cc. The total LIF signal expected $\left(A=10^{6} / \mathrm{s}\right.$, $E \gg E_{3}$, other values as given above) is

$$
\begin{aligned}
S & =0.01 \times 10^{8} \times 1 \times 1 / 2 \times 10^{-7} \times 10^{6} \times 0.001 \times 0.1 \\
& =5 \text { counts per second, }
\end{aligned}
$$

which is less than the background generated by a cooled, low-noise detector. (Detector noise may be as low as $10 \mathrm{cps}$; ours is -25 cps per channel at $-40^{\circ} \mathrm{C}$.) with 25 cps detector background and 5 cps signal, a signal to noise of 10 may be achieved with an integration of 2 min.

In our experiments, because the fluorescence is dispersed into individual lines, the appropriate value of the Einstein coefficient is $10^{4} / \mathrm{s}$; thus we have the higher detection limit of $10^{-9} \mathrm{~atm}$. It should be emphasized that this is an optimistic calculation; it does not consider impurity quenching, reaction, or dissociation. At a temperature of 
$300^{\circ} \mathrm{C}, 10^{-11}$ atm of iodine vapor is 998 dissociated ${ }^{9}$ and contains only about $10^{6} \mathrm{I}_{2}$ molecules/cc.

For atomic species, the prospects for LIF are certainly better since dissociation is not a concern and all of the atoms are in the same initial state: It is indeed possible to detect atomic species at pressures as low as $10^{-14}$ atm if the transition is strong, if quenching and other impurities can be eliminated, and if an appropriate laser is available. In practice, the last two conditions may be extremely difficult to fulfill.

\section{ALTERNATIVES TO LIF}

As stated earlier, the object of this experimental program is to provide meaningful data about the sorption and desorption behavior of relevant fission product species. The key term is relevant. Given the reactivity of the elements and the abundance of impurities, it is extremely unlikely that free fission product atoms exist in the cooling circuits. Before any additional effort is given to the development of species-specific detection techniques, the identities of the species should be established.

LIF and other species-specific techniques may be disadvantageous for this application even if the species are known. Cesium, for example, may be present in the system as Cs, CsI, CsOH, CsO, or $\mathrm{Cs}_{2} \mathrm{O}$, just to name a few possibilities. Species-specific detection requires a separate set of experiments (often involving different equipment) for each species. 
A more effective approach to this problem is to develop an experimental technique that yields meaningful results for all species and that indicates which species are present. Two techniques that are considered promising are mass spectrometry and absorption spectroscopy.

Both techniques provide direct indications of the species present and may monitor all species in a single experiment. The relatively inexpensive mass spectrometers sold as "residual gas analyzers" are capable of real time detection of species at $10^{-14}$ atm and in the presence of at least a $10^{6}$-fold excess of background gas. For absorption spectroscopy a long path gas cell could be used, or the sample gas could be condensed on a cold spectroscopic window. An experimental plan employing absorption spectroscopy is being prepared; a very high quality spectrophotometer is already available.

\section{CONCLUSIONS}

It has been demonstrated that molecular LIF lacks the sensitivity needed for fission product sorptivity measurements at the levels of interest. Under carefully controlled conditions, conditions which do not approximate those of the HTGR, atomic LIF does possess the required sensitivity for some elements. In all likelihood, however, the relevant species are not atomic in nature. It is strongly recommended that efforts be directed toward establishing the identities of species in this system. 


\section{REFERENCES AND NOTES}

1. B. F. Myers and H. H. Streckert, Sorptivity Measurements by Laser-Induced Fluorescence: An Evaluation, HTGR-85-056, GA Technologies Inc., June 1985.

2. Iodine atomic energy levels taken from C. E. Moore, Atomic Energy Levels, vol. 3, NSRDS-NBS 35, U.S. Government Printing Office, Washington, 1971.

3. Molecular iodine energies taken from P. Luc, J.Mol. Spectrosc. 80,41 (1980), and from F. Martin, R. Bacis, S. Churassy, and J. Verges, J, Mol, Spectrosc. 116, 71 (1986).

4. This was determined by using molecular constants given in the references above and by calculating energy differences for ground state levels $\mathrm{v}-0-4, \mathrm{~J}=0-120$, and excited state levels $\mathrm{v}^{\prime}=30-55, \mathrm{~J}^{\prime}=\mathrm{J} \pm 1$.

5. The vapor pressure of $I_{2}$ was calculated as

$$
\log _{10} P(\text { torr })=A-B /(T+C) \text {, }
$$

where

$$
\begin{aligned}
& A=9.8109, \\
& B=2901, \\
& C=256, \\
& T=\text { the temperature in }{ }^{\circ} \mathrm{C} .
\end{aligned}
$$

The equation is taken from Lange's Handbook of Chemistry (McGrawHill, 1979).

6. The signal expression is adapted from J. D. Winefordner and M. Rutledge, Appl. Spectrosc. 39, 377 (1985).

7. This is the fraction of molecules in the ground state sublevels $v$, J, that are connected to the excited state by the laser frequency. For our case, it is the fraction in $\mathrm{v}=0, \mathrm{~J}=51$ or 54. This fraction is given by

$$
\alpha_{v J}=\frac{(2 J+1) \exp [-h c B J(J+1) / k T] \exp [-v h c v / k T]}{(k T / h c B)[1 /(1-\exp [-h c v / k T])]},
$$

where

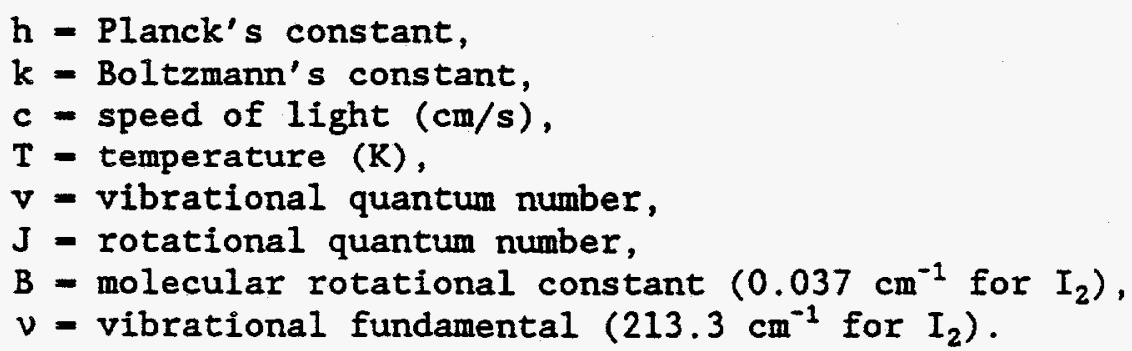


8. The Einstein coefficient is given by

$$
A=64 \pi^{4} \mu^{2} / 3 h \lambda^{3}
$$

where

$$
\begin{aligned}
& h=\text { Planck's constant, } \\
& \lambda=\text { emission wavelength, } \\
& \mu=\text { transition strength. }
\end{aligned}
$$

For molecules, $\mu^{2}$ is approximated as $\mu^{2} \times$ FC, the product of an average electronic transition strength with the Franck-Condon factor for the particular sublevels involved. Franck-Condon factors for $I_{2}$ are given by Martin et al. in ref. 3 .

9. In the absence of any background gas, the percent dissociation of $I_{2}$ may be written as

$$
D=\left[K_{p} /\left(K_{p}+4 P\right)\right]^{1 / 2} ;
$$

where

$$
\begin{aligned}
& \mathbf{P}=\text { total pressure of molecular and atomic iodine, } \\
& \mathrm{K}_{\mathrm{p}}=\text { equilibrium constant for dissociation. }
\end{aligned}
$$

Values of $k_{p}$ are derived from JANAF Thermochemical Tables, NSRDS-NBS 37, U.S. Government Printing Office, 1985. 

DOE - HTGR -88298

ORNL-6553

Distribution

Category UC -522

\section{INTERNAL DISTRIBUTION}

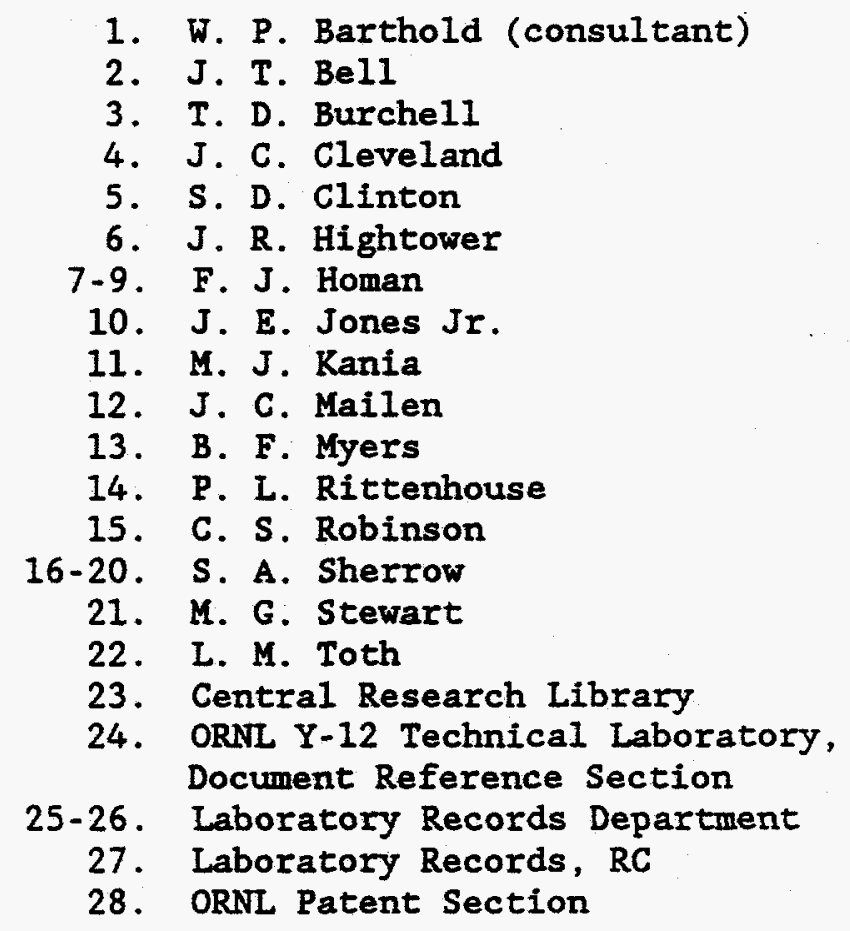

EXTERNAL DISTRIBUTION

29. Bechtel National, Inc., P.0. Box 3965, San Francisco, CA 94119

D. Dilling

30. Combustion Engineering, Inc., 1000 Prospect Hill Road, Windsor, CT 06095
A. D. McWhirter

31. Department of Energy, Washington, DC 20545

Division of HTGRs

A. C. Millunzi, Director

J. E. Fox

M. E. Long

32. Department of Energy, Oak Ridge Operations Office,

P.O. Box 2001, Oak Ridge, TN 37831

Office of Energy Research and Development

Director, Energy Programs Division

Attn: L. K. Price/G. Santos-Leon

Energy Technology Branch

G. C. Manthey, Chief 
33. Department of Energy, San Francisco Operations Office, 1333 Broadway, Oakland, CA 94612

S. Wookey

34. EG\&G-Idaho, P.O. Box 1625, Idaho Falls, ID 83415

E. Arbtin

35. General Atomics, P.O. Box 85608, San Diego, CA 92138

A. J. Neylan

36. Gas-Cooled Reactor Associates, 10240 Sorrento Valley Road, Suite 300, San Diego, CA 92121

L. D. Mears

37. MHTGR Plant Design Control Office, P.0. Box 85608, San Diego, CA 92138

R. R. Mills

38. Stone and Webster Engineering, Inc., P.O. Box 2325, Boston, MA 02107

W. C. Craig

39-94. Office of Scientific and Technical Information, P. O. Box 62, Oak Ridge, TN 37831 